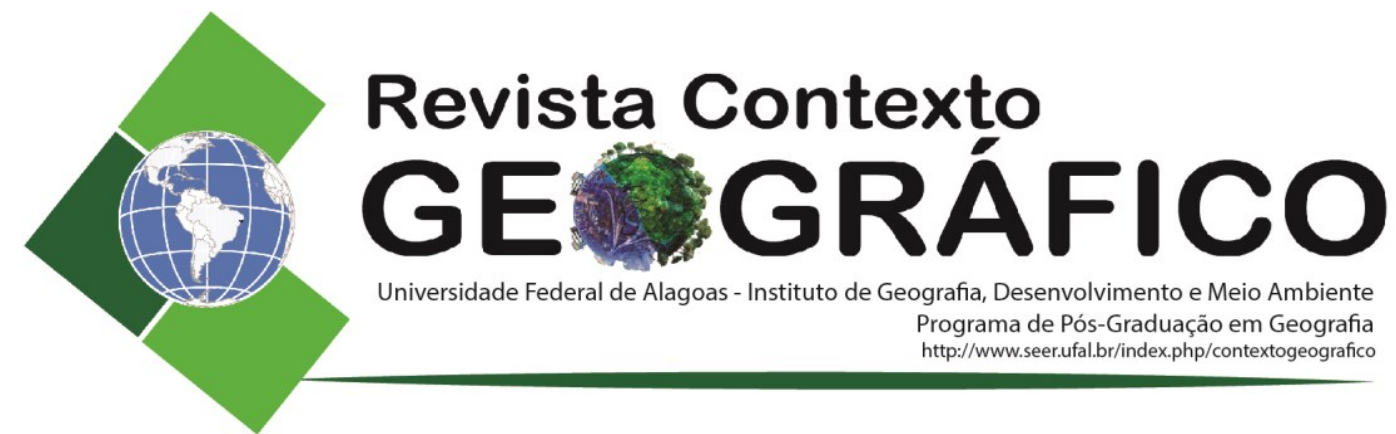

\title{
O RIO, A FRONTEIRA E O URBANO COMO ELEMENTOS DEFINIDORES DA CIDADE DE BOA VISTA - RORAIMA
}

\author{
Paulo Rogério de Freitas Silva \\ Universidade Federal de Alagoas, Instituto de Geografia, Desenvolvimento e Meio Ambiente, \\ Maceió, AL, Brasil \\ paulgeografia@gmail.com
}

\begin{abstract}
RESUMO - Iniciamos destacando que Boa Vista, localizada às margens do rio Branco e aos pés da serra Grande possui o significado de um lugar impregnado de categorias formadas a partir da materialidade desse espaço. Esse lugar moldou o setentrional amazônico pela sua unicidade e importância, pois é lá onde os movimentos ocorreram e ocorrem, com sua pluralidade, com seus diferentes povos. Não se trata de uma cidade amnésica, pois, Boa Vista tem responsabilidade e responde pela estruturação e organização de Roraima, seja como território ou estado. A sua influência ultrapassa os limites territoriais do estado e do Brasil, alcançando a Venezuela e a República Cooperativista da Guiana nas suas margens, ultrapassando as barreiras burocráticas, desempenhando um papel de destaque como articuladora entre o internacional, o nacional, o regional e o local, como destaca Silva (2007). É a capital da Guiana Brasileira, da ponta de lança que se insere entre a Venezuela e a República Cooperativista da Guiana. E é o seu significado no contexto regional fronteiriço Brasil - Venezuela - Guiana que buscamos alcançar. Acrescentamos que essa análise busca verificar as singularidades que se apresentam nessa fronteira, como um processo diferenciado de ocupação e povoação do restante da região amazônica.
\end{abstract}

PALAVRAS-CHAVES - Amazônia; ocupação; planejamento; regional; significados

\section{THE RIVER, THE FRONTIER AND THE URBAN AS DEFINING ELEMENTS OF THE CITY OF BOA VISTA - RORAIMA}

\begin{abstract}
We began by pointing out that Boa Vista, located on the banks of the Branco River and at the foot of the Grande mountain, has the meaning of a place impregnated with categories formed from the materiality of this space. This place shaped the Amazonian north by its uniqueness and importance, because that is where the movements took place and occur, with their plurality, with their different peoples. It is not an amnesic city, because Boa Vista has responsibility and responds by structuring and organizing Roraima, whether as territory or state. Its influence extends beyond the territorial boundaries of the state and Brazil, reaching Venezuela and the Cooperative Republic of Guyana on its banks, overcoming bureaucratic barriers, playing a prominent role as an articulator between international, national, regional and local, as highlighted by Silva (2007). It is the capital of Guiana Brasileira, the spearhead that enters between Venezuela and the Cooperative Republic of Guyana. And it is its meaning in the regional frontier Brazil - Venezuela - Guyana that we seek to achieve. We add that this analysis seeks to verify the singularities that present in this border, as a differentiated process of occupation and settlement of the rest of the Amazon region.
\end{abstract}

KEYWORDS - Amazonia; occupation; planning; regional; meanings

\section{A COMPLEXIDADE GENÉTICA DE BOA VISTA}

Destacamos que o município de Boa Vista apresenta essa denominação em referência à paisagem que a circunda, pois esta foi aclamada por sua grande beleza, formada pelo rio Branco, pelos igarapés, pela vegetação ribeirinha e pelas praias que ali se formam, quando ali se 
estabeleceram os primeiros desbravadores ou, como relata a história, pela admiração do Capitão Inácio Lopes de Magalhães.

Esse capitão do Forte de São Joaquim foi o fundador da fazenda Boa Vista, tendo nas suas circunvizinhanças surgido um povoado, que posteriormente, sediou a Freguesia de Nossa Senhora do Carmo e depois a sede do município de Boa Vista do Rio Branco.

Segundo Magalhães (1987, p.70), se aventou a possibilidade de mudar esse nome para Parima ou Uailã ou outra designação ligada à região, por causa da coincidência com outras cidades, também chamadas de Boa Vista em outros estados brasileiros. Mas, em razão das reivindicações, de outros grupos, para que se mantivesse o nome original, esse permaneceu.

Atualmente, a capital do estado de Roraima concentra uma população de 284.313 habitantes, em seu município, segundo o Censo Demográfico do IBGE (2010), tendo uma densidade demográfica de 49,99 habitantes por quilômetros quadrados.

Amparados em Ferri (1990, p.08), ao analisar o fluxo migratório que se processa em Roraima do interior para a cidade e só raramente em sentido contrário, a autora coloca que Boa Vista vem sendo definida como a "maior maloca de Roraima."

Essa cidade, durante o século XIX e nas primeiras décadas do século XX, foi o único lugar considerado urbano em toda a região do rio Branco, apesar de sua simples estrutura na época.

Amparados em Barbosa (1993-1, p.134), verificamos que a população de Boa Vista e de seus arredores, no final do século XIX, totalizava em média 1.000 indivíduos. O povoado era formado por 27 casas no ano de 1888, que confirma a existência de uma pequena população urbana, formando um povoado que servia de base comercial para toda aquela área.

Outra descrição do período é de Magalhães (1987, p.138) que comenta que, na penúltima década do século XIX em Boa Vista, mais precisamente no ano de 1881, existiam apenas duas casas e em 1889, quando da Proclamação da República brasileira, se contabilizavam 27 casas, entre as quais apenas uma de pedra, assim como também a igreja cuja construção já estava bastante adiantada.

Dessa forma, nos antecipamos a concluir que, quando da emancipação política da Vila de Boa Vista do Rio Branco em 1890, está ainda era um pequeno aglomerado, predominando construções de barro cobertas de palha, com uma pequena população, que se ocupava principalmente de atividades ligadas ao setor primário.

Como a principal base da economia local era a pecuária esta não demandava grande quantidade de mão de obra, além de que as sérias dificuldades de acesso à área influíam no processo migratório, que era esparso. Essa realidade proporcionou uma simples estrutura urbana da então Vila de Boa Vista do Rio Branco e a distribuição da pequena população regional, que residiam principalmente nas diversas fazendas localizadas ao longo dos rios.

Todavia, baseados novamente em Magalhães (1987, p.139), verificamos que na virada do século XIX para o XX, após a criação do município, ocorreram fluxos migratórios, ainda que pequenos, que provocaram uma efetiva colonização. Esses migrantes provinham da própria região Norte, tendo como causa a crise do ciclo da borracha em outras áreas da região.

Com o início da crise desse ciclo econômico, deu-se a dispersão dessa população para outras áreas da Amazônia, inclusive para a região do rio Branco, que atraiu esses migrantes em virtude da descoberta da existência das reservas minerais e da expansão da atividade pecuária que ocorria nesse período, principalmente na década de 1910.

Ressaltamos também, que esse processo migratório ocorreu também, diretamente do Nordeste brasileiro que, com seus problemas fundiários, já expulsava o povo nordestino que buscava, entre outras áreas, as do Rio Branco, no afã de melhores condições de vida. 
Nesse período, os imigrantes se destinavam principalmente às fazendas do vale do rio Branco, que condicionava ainda uma distribuição espaçada da população, disposta, sobretudo, nas diversas sedes das fazendas, permanecendo em Boa Vista uma pequena parcela, o que implicava em uma população urbana inferior à rural, sendo Boa Vista um simples povoado na fronteira.

Assim, mesmo com esses deslocamentos, a distribuição da população continuou rarefeita nessa área com predominância no campo, isto é, nas fazendas de gado. O rio Branco foi importante para a localização do ajuntamento humano inicial que foi crescendo nessa fronteira.

$\mathrm{O}$ aglomerado, que primeiro foi se formando em terras da fazenda Boa Vista, às margens do rio Branco, próximo ao ancoradouro, tinha esse afluente do rio Negro como única via de comunicação e circulação. Esse recurso hidrográfico influenciou o crescimento do povoado às suas margens, aproveitando-se também da topografia plana da área.

A cidade de Boa Vista em 1917, para J. Santos (2004, p.82), “(...) tinha ainda um aspecto de vila solitária e isolada da Capital do Amazonas e do resto do País". Porém, para esse pesquisador, essa cidade, "Implantada em posição geográfica dominante, à margem direita do Rio Branco, já apresentava nessa época, casas bem construídas, com mistura de pedras e cal, cobertas de telhas, bem cuidadas e pintadas com cores alegres e uma bela capela que causava boa impressão a qualquer visitante.

Tinha ao todo quarenta e nova residências, entre casas e barracos, que eram dispostas separadas umas das outras, por certa distância, dando uma impressão de espaço ocupado bem maior do que o real. Ali residiam, na década de 1910, cerca de trezentos habitantes que se ocupavam da pecuária e da garimpagem.

Para se ter outro exemplo do que era Boa Vista, em 1924, durante a expedição de Hamilton Rice, este descreve que Boa Vista era o único agrupamento junto ao rio que tinha a possibilidade de ser chamado de vila quando se observa o simples traçado urbano do período.

Esse aglomerado compreendia 164 casas que abrigavam uma população de 1.200 pessoas. Alguns dos edifícios que formavam o conjunto arquitetônico local eram de tijolos, tais como a igreja, a intendência, algumas casas de moradia e o armazém, porém, a maioria era de reboco e pau-a-pique.

A população local se compunha de portugueses, brasileiros, mestiços, índios e alguns negros vindos das Índias Ocidentais pela Guiana Inglesa, aliás, em número muito reduzido (RICE, 1978, p.25).

Para Macaggi (1976, p.109 e 110), Boa Vista era um

(...) vilarejo até 1926 , pequenina e triste, possuía na ocasião regular número de habitantes. Muito espalhada, com poucas casas de alvenaria e inúmeras de taipa, cobertas de palha de buriti ou inajá. Sem árvores, sem praças e sem flores. Prédios velhos e feios. Quintais abertos e abandonados, sem uma horta ou jardinzinho. Só um bangalô, à distancia, embelezando a paisagem. Nenhum grupo escolar, sendo raras suas escolas, regidas por professores primários. Sem cáis e as margens do rio terríveis para a atracação das embarcações.

Essas duas últimas descrições nos demonstram a situação do lugar na década de 1920, quando Boa Vista apresentava uma condição de sede de município amazônico, apresentando características muito simples, que permanecem no decorrer das décadas de 1930 e 1940 , quando, então, torna-se capital de território.

Em Farrar \& Rinehart (1934, p.15 e 17), a partir da descrição feita pelo novelista inglês WAUGH, esse lugar, diante de sua primeira visão, a partir da margem esquerda do rio Branco era "uma confusão de casas em ruínas", quando ali chegou em 1934. A rua central de Boa Vista era, “(...) larga, com piso de barro ressecado e desnivelado, com largas fendas por toda parte e 
sulcado por várias sarjetas secas. As casas caiadas, cobertas de telhas, de um só andar, eram enfileiradas de um lado e do outro da rua".

Para esse novelista, a prelazia dos Beneditinos era o edifício mais imponente, maior que as demais construções que havia visto desde que partira de Georgetown, na então Guiana Inglesa, rumo ao lugar Boa Vista. Ainda Waugh, em Farrar \& Rinehart (1934, p.20), descreve que:

Havia a rua central pela qual nós chegamos - Rua Bento Brasil - duas estradas paralelas menos importantes e mais quatro outras ruas que a cortavam em ângulo reto. Em todas as direções depois de uns 400 metros, as estradas sumiam aos poucos, se transformando em vagarosos caminhos.

Assim, esse lugar isolado se mostrava ou aparecia ao mundo através da visão destes exploradores que ali passavam e lhe descreviam. Era o lugar do contato com o "urbano" para os primeiros habitantes que se dedicavam à pecuária e ao garimpo. Era o urbano na infinita Amazônia em transição para o "lavrado", o único depois de Manaus para quem buscava o norte em direção à Venezuela e à Guiana ou o primeiro para quem descia desses países.

Exercia influência comercial em uma ampla região composta por fazendas, garimpos, aldeias indígenas; aí foi se fortalecendo até se transformar na capital do Território Federal do Rio Branco em 1943, que passaria a ser denominado de Roraima em 1962.

Conforme Barros (1995, p.61 e 62):

Certamente que a criação do Território foi responsável, ao lado da mineração que usava Boa Vista como base de apóio, pelo crescimento populacional e ultracentralização funcional desta cidade, ao longo das décadas de 1940 e 1950, e que se acentuará nas seguintes.

Da mesma forma, Ferri (1990, p.24) aponta que:

De acordo com os dados do IBGE, no período compreendido de 1920 a 1950, houve um aumento populacional de Boa Vista de $80 \%$ aproximadamente, a partir da criação do Território Federal do Rio Branco. Pode-se atribuir esse aumento ao declínio da extração da borracha na Amazônia e à instalação administrativa do território.

Nesse processo, como a única cidade da região do Rio Branco, Boa Vista foi centralizando as funções que iam sendo implantadas no território, não havendo um processo em que elas se deslocaram de um centro para outro, assim como foi o destino da maioria dos migrantes, que se dirigiam principalmente para essa cidade.

Com isso, foi ocorrendo à concentração e a formação do contraste entre Boa Vista e os demais aglomerados; ela foi aumentando e criando essa cumulativa estrutura atual.

Segundo Ferreira et ali (1977, p.82), quando este se remete as capitais de estados e territórios federais da Amazônia recém-criados, “(...) elas exis[tiam] mais como centros burocráticos do que como polos de vida e desenvolvimento." Podemos propor que Boa Vista tinha um papel que se resumia a um simples centro administrativo.

Indicamos que a localização geográfica de Roraima, junto à fronteira interferiu como determinante organizador, pois a história da cidade de Boa Vista está partilhada por eventos que indicam a importância dessa localização geográfica, que passa a atender a interesses nacionais. Sugere-se que o projeto de Boa Vista como capital de território está ligado a questões de interferência na fronteira, que precisava ser protegida.

O pequeno aglomerado, que se transformou na capital roraimense em 1943, era um espaço que apresentava poucas condições, através das quais o urbano planejado foi sendo produzido. 
Havia um grande vazio demográfico e um reduzido número de pequenos aglomerados no vale do rio Branco, excetuando-se Boa Vista que, como destacou RICE (1978), era o único lugar que poderia ser chamado de vila.

\section{O PLANEJAMENTO DO URBANO NA FRONTEIRA}

Boa Vista do Rio Branco parecia querer reagir a certos momentos, redirecionando ou modificando as condições pré-existentes de um lugar da fronteira, onde se vinculavam o limite imposto e a necessidade de torná-los visíveis e delimitáveis, como o poder através do urbano naquele limite.

A partir desse pequeno núcleo pré-existente, planejou-se uma cidade que pudesse exercer o papel do poder central na fronteira e demonstrar o significado de Brasil potência, para os que pudessem apreciar o novo urbano inspirado em Belo Horizonte, havendo considerações de que a cidade também foi projetada com inspiração em Paris, em uma alusão às ruas da capital francesa. $\mathrm{O}$ núcleo embrionário tornou-se o centro do poder brasileiro naqueles confins amazônicos.

Dessa forma, uma das formas de entender Boa Vista é a sua posição nessa parte da fronteira amazônica, limitada pela Venezuela e pela Guiana que compõem a divisão geopolítica sulamericana. Uma fronteira que fugiu à bipolaridade da hegemonia portuguesa e espanhola na América do Sul na época da colonização, quando o Reino Unido da Grã-Bretanha também dominou esse espaço, em conjunto com a Holanda e a França.

Dessa forma, o planejamento de uma cidade nesse espaço nos remete a uma intervenção de interesses políticos, já que a dimensão do lugar no período se submete a esse fim, para proteger essas plagas. Questão compartilhada também por A. S. Júnior (1993, p.113) que afirma que, "O surgimento de núcleos populacionais nessa faixa de terra do extremo norte do País foi resultado da necessidade de defender as fronteiras do Brasil de invasões estrangeiras."

Essa citação nos remete à complexidade genética dos lugares urbanos nesse espaço e ao planejamento urbano criado para Boa Vista em 1946, quando se definem as estratégias de organização do espaço nacional brasileiro.

Acreditamos que esse planejamento de Boa Vista está presente no projeto geopolítico nacional, que criou para a Amazônia, planos nacionais de desenvolvimento, na intenção de ocupar e povoar essa área. A implantação de novas cidades projetava a força do poder central nesse espaço, questão defendida por Becker (1998, p.46), afirmando que "a fronteira atual já nasce urbana, como uma estratégia de ocupação utilizada pelo Estado".

Becker $(1998$, p. 53, 54, 55) ainda, quando analisa a urbanização como estratégia de ocupação na Amazônia, coloca que o núcleo urbano atrai o imigrante, é à base da organização do mercado de trabalho, assim como é o lugar da ação política-ideológica do Estado.

Nessa conjuntura, ressaltamos, que para a realidade brasileira, o surgimento dos núcleos urbanos, além de sua espontaneidade com suas cidades coloniais, primeiro localizadas na costa, tais como Salvador e Olinda até as nossas cidades planejadas, se passaram mais de quinhentos anos de ocupação e estruturação que se mostram subdivididas nas atuais cinco macrorregiões com suas respectivas particularidades no que se refere ao número e tamanho de cidades.

Com essa estrutura, onde se reúnem o espontâneo urbano e o plano urbano, no Brasil se criaram várias cidades que Santos (1988, p.42) define como "cidade artificial", tais como Belo Horizonte, Volta Redonda, Goiânia, Londrina, Brasília, considerando esses projetos urbanos experiências que casavam filosofia, sociologia e política com a prancheta.

Com relação a esses projetos urbanos, resgatamos de Vicentini (2004, p.236), que quatro cidades foram planejadas como cidades capitais no Brasil, a partir da segunda metade do século XIX até meados do século XX: a primeira teria sido Teresina, em 1852, concebida como cidade 
capital do Piauí; a segunda, Belo Horizonte, em 1897; a terceira, Goiânia em 1935; e a quarta, Brasília, em 1960. A autora destaca que, mais recentemente, na segunda metade do século XX, teria sido Palmas a mais nova capital brasileira implantada.

Ainda nessa conjuntura, encontramos em Oliveira (1992) que, no Brasil, foram planejadas: Belo Horizonte cujo plano foi elaborado em 1896; Goiânia, projetada entre 1933 e 1937 e implantada em 1939; Volta Redonda, que surge em 1943 como cidade industrial no estado do Rio de Janeiro; em 1960 seria a vez de Brasília, que passaria a ser a sede do poder administrativo brasileiro.

Porém, Santos (1988, p.40) afirma que o planejamento físico-territorial não é novidade no Brasil, porque, [r]emexedores de mapas e papéis velhos conseguiram provar que muitas cidades disseminadas pelo Brasil afora cruzaram o Atlântico sob a forma de "riscos" (traçados reguladores) e regulamentos que ordenavam a boa disposição espacial, o abastecimento e a defesa, muito antes que se lançasse sua pedra fundamental. Foi assim, por exemplo, que se conquistou a Amazônia.

Essa condição é analisada e compreendida considerando, a cada momento, as transformações regionais que ocorreram, de acordo com os diversos períodos que formalizaram o tempo histórico regional, desde a implantação do Forte do Presépio em 1616, que originou Belém, passando pelo ciclo da borracha, e diversos outros importantes momentos até chegar ao presente.

Nesse sentido, concordamos com Oliveira (1992, p.38), ao advogar que:

\begin{abstract}
Na Amazônia o desenho estará presente no projeto geopolítico nacional, nos planos nacionais de desenvolvimento, nas cidades planejadas e/ou projetadas para a região, nas intenções da iniciativa privada, em diferentes níveis, até mesmo na implantação integral de novas cidades, como também, nos propósitos da população ao projetar em escala um para um suas novas cidades.
\end{abstract}

Diante dessas questões, entres esses processos citados e em um período que pode ser considerado recente, década de 1940, o planejamento urbano de Boa Vista está correlacionado a um plano geopolítico estratégico na fronteira amazônica.

O que nos chama a atenção é que esse lugar talvez, por ter sido um plano urbanístico implantado a partir de um núcleo urbano embrionário pré-existente, não seja citado como uma cidade planejada na Amazônia e no Brasil. Desconhece-se, na literatura existente, esse projeto urbanístico, idealizado pelo primeiro governador do território, Êne Garcez, e planejado pelo engenheiro Darci Aleixo Derennusson, implantado em 1946, tendo essa implantação se dado aos poucos, mais precisamente entre 1947 e 1950, com um formato radioconcêntrico.

Esse projeto urbano implantado em Roraima em 1946 foi um evento que mudou a figura de Boa Vista, começando um novo período na história dessa cidade, transformando-a, como afirma Barros (1995, p.151), é um “(...) projeto de 'foreworld city', uma cidade que mostrasse na fronteira o que o poder central se propunha a ser."

Planejar uma cidade como Boa Vista na fronteira significava a necessidade de intervenção de interesses públicos para proteger a referida área. $\mathrm{O}$ que ocorreu, na realidade, foi à construção de um centro burocrático e uma base militar. Esse lugar tinha um papel geopolítico na região, tornando-se um polo artificialmente criado, marcando os limites internacionais do Brasil. O que mais chama a atenção é a ausência de uma base econômica consolidada, que pudesse gerar uma economia sólida na área, contudo, a principal fonte de renda do território era como lugar estratégico que dependia de recursos do poder central.

Esse plano urbanístico ou, como denomina Barros (1995, p.150), plano básico, foi implantado a partir de uma pequena aglomeração composta por três ruas, paralelas ao rio Branco que tinha o porto fluvial como o nó principal e para onde se debruçavam os edifícios públicos, as casas comerciais e a igreja católica. 
Boa Vista era um pequeno aglomerado urbano e havia uma preocupação com uma melhor urbanização e ocupação do novo Território do Rio Branco.

Para se ter uma ideia, a sede do município de Boa Vista em 1944, quando aqui desembarcou o primeiro governador do território federal, Capitão Êne Garcez, agrupava 5.248 habitantes, três ruas paralelas ao rio Branco, algumas casas de alvenaria e a quase totalidade de taipa e coberta de palhas (FREITAS, 1993, p.32).

Para Barros (1995, p.151), a "estrutura urbana herdada deste período é representada por lotes estreitos de casas conjugadas de ambos os lados, ao velho estilo lusitano, acomodando-se às oscilações do relevo ribeirinho".

Dessa forma, foi elaborado um plano no qual foi sugerido que a partir desse núcleo se criasse um traçado. O projeto da cidade é arrojado e intencionava a implantação de avenidas radiais a partir de um centro cívico, onde os lotes foram destinados na época, para construção de residenciais e de repartições públicas que precisavam ser instaladas. Nessa proposta, buscava-se programar uma cidade que tivesse uma estrutura para servir aos novos residentes que para ali se destinavam, através da instauração da máquina burocrática.

O traçado tem uma estrutura radial concêntrica, privilegiando um único centro, tendo seu início às margens do rio Branco, configurando-se na paisagem urbana o poder centralizado. Essa estrutura favorece uma centralização para o qual tudo converge, polarizando praticamente todas as atividades urbanas, administrativas e comerciais. Nesse sistema, as vias principais são radiais, sendo dezesseis ruas e avenidas que partem da praça central denominada de centro cívico e, à medida que se prolongam, acompanhando o crescimento da cidade, se distanciam entre si, formando uma estrutura em forma de leque.

$\mathrm{Da}$ "bola", popularmente chamada pela população a praça circular, onde se localiza o palácio Hélio Campos, sede do governo estadual, partem essas ruas e avenidas, que são radiais, em direção ao norte, oeste e sul, tais como, Ville Roy, Capitão Julio Bezerra, Mario Homem de Melo, Ene Garcez, Getúlio Vargas, Glaycon de Paiva, entre outras. Circulando a praça estão as repartições públicas, a catedral católica, alguns bancos, o principal hotel da cidade e algumas casas comerciais.

No decorrer do século XX, a cidade de Boa Vista cresceu ultrapassando os limites possíveis desse projeto radial concêntrico, formando uma estrutura urbana que foge ao plano original proposto, alterando o seu tecido urbano original.

Tendo havido nesse contexto, mudanças no sítio urbano, que para Beaujeu-Garnier (1997, p.76), designa o lugar preciso da implantação inicial da cidade.

Verificamos baseados em Hilhorst (1973, p.85), que, “(...) os limites da área de influência de uma cidade tendem a modificar-se com o tempo", já que muitos fatos novos podem ocorrer, alterando os limites de uma área de influência.

Na realidade da região do Rio Branco, Boa Vista apresenta-se pioneiramente como uma Freguesia e depois sede de município do estado do Amazonas detendo uma influência que alcançava as áreas rurais mais próximas. Quando chega à condição de capital de Território Federal, tem seu poder, no sentido político administrativo formalizado para todo o espaço geográfico do território, que se consolida com a transformação deste em estado, o que nos coloca em sintonia com a ideia de (HILHORST, 1973).

Em princípio, baseados em Becker (2006:73), ressaltamos que com relação à ocupação regional, o "padrão linear", patrocinou a integração terrestre e fluvial da Amazônia, em torno dos quais se concentraram investimentos públicos e privados. 
Sendo assim, a ocupação flúvio-linear, no princípio da ocupação roraimense, foi determinante para o tipo de influência que o lugar único, Boa Vista, poderia obter com relação ao seu espaço de ação. Todavia comungando com Ferreira et ali (1977, p.23), a implantação de rede viária trouxe mudanças significativas para alguns centros, estagnando outros, quando as rodovias substituem outros caminhos, que em Roraima, se restringiam quase somente aos rios.

Mesmo assim quando os rios, como principais vias de escoamento da produção local, foram substituídos por esses novos caminhos, Boa Vista, mais uma vez, é privilegiada por se ver interligada a Manaus e a Venezuela, solidificando sua condição de cidade principal e concentradora da população e dos equipamentos, já que antes essa dependia anteriormente do porto de Caracaraí, que consequentemente, perde essa condição de cidade portuária onde se fazia o transbordo das mercadorias.

A cidade de Boa Vista, mantêm sua influência, manobrando o grande espaço riobranquense e se consolidando, inclusive deixando na retaguarda, lugares que poderiam ter tido um crescimento relativamente próximo ao seu, como é o caso de Caracaraí, tornando-se a cidade-polo em Roraima.

Contudo, constatamos que Boa Vista, cidade-polo, é uma cidade média de importância que impressiona, mas, que dentro desses padrões medianos, ainda vive um tempo lento, apesar de seu forte papel nessa fronteira, possuindo funções especializadas que dão suporte para que a mesma assuma esse papel.

Para além, acrescentamos que essa cidade exerce uma influência sobre os demais municípios de Roraima, apresentando também, novas tendências de polarização, de ordem cultural, além das de ordem financeira, especialidades médicas, na área dos transportes, ensino superior e, como centros de pesquisas e lazer. Apresenta ainda um controle sobre o território onde está inserida, fazendo com que as demais cidades, sedes de municípios do estado, permaneçam basicamente como verdadeiros satélites em torno de sua economia.

Ao analisar a disponibilidade de determinadas funções nos amparamos em Claval (1991, p.409), quando este argumenta que,

O setor moderno só se implantou em um pequeno número de pontos ou de regiões, sendo essa concentração em muitos casos tão grave que dificulta, quando não impede, o desenvolvimento de cidades intermediarias, de centros pequenos, de centros locais e até de zonas rurais.

Argumentação que representa a realidade de Roraima quando Boa Vista acumulando funções e sendo prestadora de serviços de inúmeras qualidades, sofreu ações de modernidade no campo das telecomunicações e dos transportes, determinando essa configuração espacial em detrimento dos demais lugares do estado.

Para Fernandes Neto (2003, p.23),

Apesar da fragilidade das estruturas de ocupação territorial, dados sobre o movimento aéreo mostraram uma grande articulação da capital do estado com outras capitais e cidades do país, principalmente do Centro-sul, onde se localizam as sedes das firmas e companhias que atuam em Roraima.

Boa Vista é a única cidade de Roraima, que dispõe de serviços de transporte aéreo de passageiros e cargas com periodicidade, tendo uma frequência de cinco voos diários nacionais para as principais cidades brasileiras, servida pelas principais companhias aéreas do Brasil, assim como, com a frequência de voos sazonais, através de pequenas companhias aéreas locais, que interliga Boa Vista as cidades de Georgetown na Guiana e Paramaribo no Suriname, com conexões para vários países do mundo, que são realizados nos aeroportos do 
Brasil e desses outros países, tendo além do mais, a partir de Santa Elena do Uairen, voos para algumas cidades venezuelanas.

Outro aspecto que se destaca é de que a cidade de Boa Vista apresenta-se como um polo universitário (ensino, pesquisa e extensão), oferecendo cursos de graduação e pós-graduação, onde se destacam a Universidade Federal de Roraima - UFRR, a Universidade do Estado de Roraima - UERR, o Instituto Federal de Ensino Superior/ IFET - RR, como instituições públicas em conjunto com as demais instituições particulares ali instaladas, que fortalecem o campo cientifico, através da implementação de pesquisas e da formação de mão de obra qualificada, voltadas para a realidade do estado, inclusive com a permanência de alunos e profissionais de outros estados brasileiros e do estrangeiro.

Destacamos também a Empresa Brasileira de Pesquisa Agropecuária, EMBRAPA - RR, o Museu Integrado de Roraima, MIRR, o Instituto Nacional de

Pesquisa da Amazônia, INPA - RR, que como instituições de pesquisa, em conjunto, buscam acelerar o processo de difusão dos conhecimentos científicos e técnicos de Roraima, colocando o estado e Boa Vista no cenário regional e nacional.

\section{CONSIDERAÇÕES FINAIS}

Apesar da pouca representatividade de Roraima, quando comparado ao restante da região amazônica e ao Brasil, aponta-se que essa condição pode ser alterada, tendo em vista a sua privilegiada situação geográfica, que hoje é interpretada por outro viés.

Se antes foi um determinante para um crescimento lento, apresenta-se na atualidade como um impulsionador, com Roraima transformando-se na porta de entrada para o norte da América do Sul e Caribe, integrando essas regiões ao Brasil e consequentemente, ao Mercosul (Mercado Comum do Cone Sul)."

A cidade de Boa Vista passa por um processo de inserção no mercado regional a partir desses projetos, que repercutem nessa capital, tal como ressaltam AMORIM FILHO \& DINIZ (2004:07), quando destacam a importância das conexões de Boa Vista com as cidades fronteiriças e com a metrópole ocidental amazônica, Manaus.

Nessa conjuntura, a modernidade em Boa Vista também é percebida pelas formas de apropriação de áreas pelo poder público para lazer como a orla Taumanan, o parque Anauá, e também o Centro de Artesanato, além da geração de renda que está localizada no complexo poli esportivo Ayrton Senna.

Da mesma forma, as atividades culturais e de lazer que se concentram na capital, tais como cinemas que exibem filmes lançados nacionalmente, teatros com peças locais e algumas regionais e nacionais, bibliotecas, salas para conferências e shows, entre outros espaços para eventos, colaboram para essa modernidade.

Por outro lado, a modernidade é percebida em Boa Vista pela concentração das oito retransmissoras de televisão, das cinco emissoras de rádios nas faixas $\mathrm{AM}$ e $\mathrm{FM}$ e de dois jornais de circulação diária no estado.

Destacamos também que à cidade de Boa Vista comanda as ações ocorridas no campo, quando o estado de Roraima começa a figurar no mapa do agrobusiness nacional e internacional sob o impulso da soja, à medida que as atividades rurais estão se processando com maior intensidade, com a produção de soja e com a fruticultura, no vale do rio Branco. 
Roraima hoje é visto como um polo de fruticultura do Brasil cultiva-se manga, limão, maracujá, goiaba, uva de mesa sem semente e também coco, esse último destinado à produção de farinha e ao uso na indústria de panificação.

Destaca-se que o clima favorável (com chuvas concentradas e insolação), juntamente com a tecnologia avançada e profissionais qualificados, proporcionam essa produção que poderá abastecer o mercado consumidor da região, inclusive com acordos que estão sendo firmados de forma a prover algumas redes de supermercados de Manaus.

É em Boa Vista que se faz a regulação do campo, fornecendo os produtos necessários para a produção agrícola e onde se fecham os acordos comerciais. É ali que se constrói um comércio voltado para a zona rural, quando em decorrência dessas atividades surgem lojas comerciais especializadas em produtos ligados a esse setor. Assim como é o lugar de moradia dos proprietários de fazendas produtores de soja e de grande parte dos operários que se ocupam dessa atividade.

A influência de Boa Vista ultrapassa os limites do território das cidades, chegando ao rural, através de agentes territoriais urbanos e através da presença de segundas residências dos boavistenses, às margens dos rios e dos igarapés.

\section{REFERÊNCIAS}

AMORIM FILHO, Oswaldo Bueno e DINIZ, Alexandre M. A. Boa Vista, Roraima: uma cidade média na fronteira setentrional do Brasil. In: XXV CONGRESO NACIONAL Y X INTERNACIONAL DE GEOGRAFIA. Resúmenes. Valdivia: Universidad Austral de Chile, 2004.

A. S. JUNIOR, Tércio. Roraima o Brasil do Hemisfério Norte: Diagnostico cientifico e tecnológico para o desenvolvimento. Fundação do meio ambiente e tecnologia de Roraima. Boa Vista, 1993.

BARBOSA, Reinaldo Imbrósio. Ocupação Humana em Roraima. I. Do Histórico

Colonial ao Início do Assentamento Dirigido. Boletim do Museu Paraense Emilio Goeldi, 9 (1): 123 144. Belém, 1993-1.

BARROS, Nilson Cortez Crócia de. Roraima paisagens e tempo na Amazônia setentrional. Recife: Ed. Universidade Federal de Pernambuco, 1995.

BEAUJEU-GARNIER, Jacqueline. Geografia urbana. Lisboa: Fundação Calouste Gulbenkian, 1997.

BECKER, Berta K.. Amazônia geopolítica na virada do III milênio. Rio de Janeiro: Garamond, 2006. Amazônia. São Paulo: Editora Ática, 1998.

CLAVAL, Paul. Geografia Urbana. Rio de Janeiro: 1991.

FARRAR \& RINEHART, Inc. Ninety-two days the account of a tropical jorney through British Guiana and part of Brazil...By Evelyn Waugh. Publishers, New York, 1934.

FERNANDES NETO, P. Caracterização Geográfica da Faixa de Fronteira Continental Norte do Brasil. Rio de Janeiro: UFRJ, Instituto de Geociências, 2003.

FERREIRA, José Freire da Silva et ali. Rede Urbana Amazônica. Subsídios para uma política de desenvolvimento regional e urbano. UFPA, NAEA, Belém, 1977.

FERRI, Patrícia. Achados ou perdidos a imigração indígena em Boa Vista. Goiânia: 1990.

FREITAS, Aimberê. A História Política e Administrativa de Roraima de 1943 a 1985. Manaus: Editora Umberto Calderaro Ltda. 1993.

HILHORST, Jos G. M. Planejamento Regional enfoque sobre sistemas. Rio de Janeiro: Zahar Editores, 1973. IBGE. Instituto Brasileiro de Geografia e Estatística. Censo Demográfico 2010. Rio de Janeiro: 2010.

J. SANTOS, Adair. História da Livre Iniciativa no Desenvolvimento Sócio-Econômico do Estado de Roraima. Boa Vista: Fecomércio - RR, 2004. 
MACAGGI, Nenê. A Mulher do Garimpo (O romance do extremo sertão norte do Amazonas). Manaus: Composto e Impresso nas Oficinas Gráficas da Imprensa Oficial, 1976.

MAGALHÃES, Dorval de. Roraima informações históricas. Rio de Janeiro, 1987.

OLIVEIRA, Isabel Cristina Eiras de. Desejo e Desenho na Amazônia Urbana. Rio de Janeiro, UFRJ, 1992. (Dissertação de Mestrado).

RICE, Alexander Hamilton. Exploração na Guiana Brasileira. Tradução e notas Lacyr Schettino. Belo Horizonte: Editora Itatiaia; São Paulo: Ed. da Universidade de São Paulo, 1978.

SANTOS, Carlos Nelson F. dos. A cidade como um jogo de cartas. Niterói, Universidade Federal Fluminense: EDUFF; São Paulo: Projeto Editores, 1988.

SILVA, Paulo Rogério de Freitas. Dinâmica Territorial Urbana em Roraima - Brasil. PPGGH/FFLCH/USP. São Paulo: 2007 (Tese de Doutorado).

VICENTINI, Yara. Cidade e História na Amazônia. Curitiba: Ed. UFPR, 2004. 